\title{
INOVASI LAYANAN PERSIAPAN PERSALINAN (EDUKASI DAN SENAM HAMIL) PADA IBU HAMIL DI WILAYAH KERJA UPT PUSKESMAS ALAS BARAT KABUPATEN SUMBAWA
}

\author{
Fitri Setianingsih', Ayuning Atmasari², Taryono ${ }^{3 *}$ \\ 1Sekolah Pascasarjana Program Studi Manajemen Inovasi Universitas Teknologi Sumbawa \\ 2Fakultas Psikologi Universitas Teknologi Sumbawa \\ $3^{*}$ Fakultas Ekonomi dan Bisnis Universitas Teknologi Sumbawa

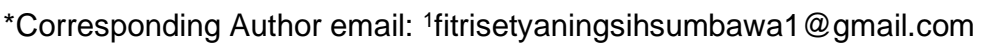 \\ 2ayuning.atmasari@uts.ac.id, 3taryonojogja1465@gmail.com
}

\begin{abstract}
Abstrak
Diterima:

Bulan Juni 2021

Proses persalinan dipengaruhi oleh tiga faktor berupa Passage (jalan lahir), Passanger (janin), Power (kekuatan). Persalinan dapat berjalan dengan normal apabila ketiga faktor terpenuhi dengan baik. Selain itu terdapat faktor lain yang mempengaruhi proses persalinan yaitu psikologis dan penolong. Angka Kematian Ibu (AKI) dapat diturunkan dengan berbagai upaya baik secara promotif maupun preventif dengan cara memberikan edukasi persiapan persalinan. Edukasi ini dapat menjadi alternatif bagi ibu hamil untuk

Diterbitkan : Bulan Juli 2021

Keyword : Ibu Hamil Ibu Brsalin Edukasi Senam Hamil Inovasi mengetahui sejauh mana perkembangan ibu dan janin, meningkatkan kemandirian ibu serta melatih menejemen koping pada stresor ibu. Senam hamil merupakan bentuk metode koping yang dapat menghindari terjadinya stress fisik akibat kehamilan, seperti mengurangi kram kaki, dan punggung, meningkatkan kemampuan ibu untuk adaptasi dengan adanya perubahan pada tubuhnya. Penelitian ini bertujuan untuk mengidentifikasi pengaruh layanan persiapan persalinan (edukasi dan senam hamil) terhadap persiapan persalinan ibu hamil di wilayah kerja UPT Puskesmas Alas Barat. Desain penelitian pre eksperiment dengan one group pretest-post test design. Instrumen yang digunakan untuk pengumpulan data adalah kuesioner. Pengujian instrumen menggunakan uji validitas Produc momen person dan uji reliabilitas. Analisis yang digunakan adalah regresi linear sederhana dengan jumlah responden sebanyak 102 orang ibu hamil. Hasil penelitian menunjukkan bahwa nilai signifikansi regresi variabel layanan persiapan persalinan (edukasi dan senam hamil) terhadap persiapan persalinan ibu hamil sebesar 0,000 atau lebih kecil 0,05. Hipotesis yang menyatakan bahwa layanan persiapan persalinan (edukasi dan senam hamil) berpengaruh terhadap persiapan persalinan ibu hamil (diterima). Berdasarkan hasil penelitian ini dapat disarankan agar ibu hamil berperan aktif dalam mengikuti kegiatan selama kehamilan agar ibu memiliki pengetahuan tentang kebutuhan selama hamil terutama persiapan menghadapi persalinan sehingga dapat meminimalisir kegawatdaruratan pada ibu maupun janin saat proses persalinan.
\end{abstract}

\section{PENDAHULUAN}

Proses kehamilan menyebabkan perubahan fisik maupun emosional ibu hamil yang berkaitan erat dengan anatomi dan fisiologi serta kejadian psikologi dan perilaku yang terbentuk baik yang disebabkan karena perubahan fisik maupun lingkungan. Perubahan ini juga dapat terjadi akibat adanya ketidakseimbangan hormon progesteron dan hormon estrogen yang ada di dalam tubuh ibu sejak terjadinya kehamilan (Irianti B, et al, 2014).

Seorang wanita yang sedang berada dalam masa kehamilan sering mengalami banyak perubahan baik secara fisik maupun perubahan psikologis yang dapat menimbulkan ketidaknyamanan. terutama pada trimester III.
Ibu hamil juga mengalami perubahan mood serta peningkatan kecemasan (Rafika, 2018). Perubahan fisik maupun psikologis yang terjadi selama masa kehamilan dapat mengakibatkan ketidaknyamanan yang berdampak terhadap kesejahteraan ibu maupun janin selama proses persalinan berlangsung.

Pada ibu yang pertama kali menjalani proses persalinan akan takut, cemas dan khawatir yang dapat berakibat pada peningkatan nyeri selama proses persalinan yang dapat menganggu proses persalinan (Wijaya dkk, 2014). Hal ini dapat menjadi kegawatdaruratan pada ibu maupun janin. Kegawatdaruratan obstetri dan neonatal merupakan suatu kondisi yang dapat mengancam jiwa ibu, hal ini dapat terjadi selama kehamilan bahkan saat proses persalinan 
berlangsung. Selama kehamilan sangat banyak sekali penyakit serta gangguan yang bisa mengancam keselamatan ibu maupun bayi yang akan dilahirkan. Kegawatan tersebut harus segera ditangani, karena jika terjadi keterlamabatan dalam menangani akan menyebabkan kematian pada ibu dan bayi baru lahir (Walyani \& Purwoastuti, 2015).

Angka kematian ibu di Indonesia lebih tinggi dibandingkan Negara-negara ASEAN lainnya. AKI di negara-negara Asean sudah menempati posisi 40-60 per 100 ribu kelahiran hidup. Sedangkan di Indonesia berdasarkan Survei Penduduk Antar Sensus (SUPAS) 2015 masih menempati posisi 305 per 100.000 kelahiran hidup. Sementara itu, data capaian kinerja Kemenkes RI tahun 2015-2017 menunjukkan telah terjadi penurunan jumlah kasus kematian ibu. Jika di tahun 2015 AKI mencapai 4.999 kasus maka di tahun 2016 sedikit mengalami penurunan menjadi 4.912 kasus dan di tahun 2017 mengalami penurunan tajam menjadi sebanyak 1.712 kasus AKI. Meski mengalami penurunan, namun AKI masih menjadi salah satu fokus utama pemerintah dalam mewujudkan masyarakat Indonesia sehat Secara nasional penyebab AKI paling tinggi adalah pendarahan (Badan Siber dan Sandi Negara, 2018).

Angka kematian ibu di Kabupaten Sumbawa meningkat signifikan selama tahun 2018. Hal itu dibuktikan dengan adanya data dari Dinas Kesehatan Kabupaten Sumbawa terkait Angka Kematian Ibu (AKI). Data Angka kematian ibu pada tahun 2017 sebanyak 4 kasus, meningkat pada tahun 2018 menjadi 12 kasus. Penyebarannya di Kecamatan Moyo Hulu sebanyak 2 kasus, Moyo Hilir 2 kasus, serta masing-masing 1 kasus di Kecamatan Lape, Lunyuk, Buer, Rhee, Alas Barat, Lenangguar, Ropang, dan Orong Telu. Penyebab kematian ibu antara lain faktor geografis jauh dari fasilitas kesehatan. Kemudian proses persalinan yang dibantu oleh dukun, serta pasien mengalami anemia atau kekurangan darah, kerena saat hamil hingga melahirkan pasien tidak patuh dalam mengkonsumsi obat penambah darah yang diberikan pihak Puskesmas atau Rumah Sakit (Profil Dinkes kab sumbawa, 2018).

Dalam upaya menurunkan angka kematian Ibu pemerintah mencanangkan program Sustainable Goals Development (SDGs) yang merupakan agenda global dalam pembangunan berkelanjutan dengan pelaksanaan dari tahun 2016 hingga tahun 2030 yang merupakan pembaharuan Millenium Development Goals (MDGs) atau agenda Pembangunan Milenium yang telah resmi berahir pada tahun 2015. Salah satu tujuan SDGs adalah terciptanya suatu kondisi kehamilan dan persalinan yang aman, serta ibu dan bayi yang dilahirkan dapat hidup dengan sehat, yang dilakukan dengan pencapaian target dalam mengurangi rasio kematian ibu secara global hingga kurang dari 70 per 100.000 kelahiran (WHO, 2017).

Angka Kematian Ibu (AKI) dapat diturunkan dengan berbagai upaya baik secara promotif maupun preventif yaitu melalui layanan persiapan persalinan. Layanan persiapan persalinan merupakan sarana untuk belajar bersama tentang kesehatan bagi ibu hamil dalam bentuk kelompok dengan cara tatap muka yang bertujuan untuk meningkatkan pengetahuan dan keterampilan ibu mengenai kehamilan hingga proses persalinan. Dengan begitu ibu hamil dapat melakukan sharing dan diskusi dengan sesama ibu hamil lainnya agar lebih paham dengan kondisi kehamilannya. Inovasi ini diharapkan dapat membantu ibu hamil untuk lebih terbuka dan intens dengan tenaga kesehatan selama kegiatan berlangsung. Program yang ditawarkan dalam layanan persiapan perslinan ini adalah edukasi persiapan persalinan dan senam hamil.

Edukasi persiapan persalinan merupakan upaya promotif dan prefentif terhadap kejadian kematian ibu, penyampaian informasi kepada ibu hamil agar lebih terbuka tentang kesehatannya khususnya keluhan-keluhan yang dirasakan selama kehamilan. Edukasi ini dapat menjadi alternative bagi ibu hamil untuk mengetahui sejauh mana perkembangan ibu dan janin, meningkatkan kemandirian ibu serta melatih menejemen koping pada stresor ibu. Pendekatan edukasi merupakan pendekatan yang paling cocok terhadap upaya pemecahan masalah kesehatan masyarakat melalui faktor perilaku dibandingkan dengan pendekatan tekanan (Coercion). Perubahan yang dihasilkan oleh edukasi didasarkan kepada pengetahuan dan kesadarannya melalui proses pembelajaran sehingga perilaku tersebut diharapkan akan berlangsung lama (Long Lasting) dan menetap (Notoatmodjo, 2011).

Penelitian Gebre, Gebremariam dan Abebe (2015) menunjukan bahwa kesiapan kelahiran berhubungan dengan ibu yang mendapat informasi dari layanan antenatal, memiliki pengetahuan minimal dua tanda bahaya selama kehamilan. Sehubungan dengan hal tersebut maka perlu adanya program inovasi layanan persiapan persalinan ini untuk menunjang kesehatan dan kesejahteraan ibu dan anak dan diharapkan program ini dapat menjadi salah satu cara untuk menurunkan angka kematian ibu (AKI). 
Senam hamil merupakan bentuk aktivitas fisik yang bermanfaat karena mengembangkan otot tubuh, meningkatkan elastisitas otot panggul dan ligamentum serta menurunkan kejadian perdarahan selama dan sesudah bersalin serta dapat menurunkan kejadian fetal distress. Senam hamil merupakan salah satu kelas persiapan persalinan yang bertujuan mendorong dan melatih organ jasmani dan psikis ibu secara bertahap agar dapat menghadapi persalinan dengan tenang sehingga proses persalinan berjalan lancar dan mudah (Mubarak, 2012).

Berdasarkan data dari Dinas Kesehatan kab.Sumbawa Tahun 2018 UPT Puskesmas Alas Barat adalah Salah satu puskesmas yang memiliki Angka Kematian Ibu (AKI). Studi pendahuluan yang sudah saya lakukan di UPT Puskesmas Alas Barat jumlah seluruh ibu hamil di wilayah kerja puskesmas alas barat adalah 218 orang ibu hamil dari 8 desa di kecamatan Alas Barat dalam satu bulan terakhir yaitu Bulan Januari-Februari tahun 2020. Sehingga peneliti tertarik untuk melakukan penelitian dengan judul "Inovasi Layanan Persiapan Persalinan (Edukasi dan Senam Hamil) Pada Ibu Hamil di Wilayah Kerja UPT Puskesmas Alas Barat Kabupaten Sumbawa".

\section{LANDASAN TEORI}

Persiapan persalinan merupakan tahap awal untuk mengetahui sejak dini kebutuhan mendasar menjelang persalinan. Dengan adanya persiapan persalinan yang baik diharapkan dapat mengurangi risiko yang mungkin dapat terjadi pada saat kehamilan, persalinan, dan masa nifas (Sunarsih, 2011). Kesiapan persalinan dan penanganan komplikasi adalah proses perencanaan untuk persalinan normal dan antisipasi tindakan yang diperlukan dalam keadaan darurat (Hailu et al, 2011).

Menurut Depkes RI (2009), tujuan persiapan persalinan aman adalah agar ibu hamil dan keluarga tergerak merencanakan tempat dan penolong persalinan yang aman. Menurut Kemenkes RI (2011) persalinan dilakukan di fasilitas kesehatan dan ditolong oleh tenaga kesehatan.

1. Perencanaan persalinan dan pencegahan komplikasi

Persiapan persalinan dan pencegahan komplikasi menurut Departemen Kesehatan RI (2009) meliputi:

a. Tempat persalinan yaitu tempat yang dipilih oleh ibu dan keluarga untuk membantu proses persalinan, seperti di rumah sakit, klinik bersalin dan praktik mandiri bidan.

b. Pendamping yaitu orangyang dipercaya mendampingi ibu saat persalinan yaitu suami atau keluarga maupun kerabat dekat yang bersedia mendampingi dan mendukung ibu selama menghadapi proses persalinannya.

c. Tabungan Ibu Bersalin (Tabulin) yaitu dana atau barang yang disimpan oleh keluarga atau pengelola tabulin secara bertahap sesuai dengan kemampuannya, yang pengelolaanya sesuai dengan kesepakatan serta penggunaannya untuk segala bentuk pembiayaan serta antenatal, persalinan dan kegawatdaruratan pada ibu.

d. Persalinan oleh tenaga kesehatan yaitu persalinan ibu ditolong oleh tenaga kesehatan trampil sesuai standar seperti dokter spesialis kandungan atau bidan yang telah memiliki surat ijin praktik.

e. Transportasi yaitu alat transportasi yang dapat digunakan untuk mengantar calon ibu bersalin ke tempat persalinan termasuk rujukan dan siap setiap saat agar tidak terjadi keterlambatan mencapai tempat bersalin ibu. Transortasi bisa berupa ambulan desa, mobil pribadi maupun kendaraan roda dua atau sepeda motor.

f. Calon pendonor darah yaitu orang-orang yang disiapkan oleh ibu, suami, keluarga dan masyarakat yang sewaktu-waktu bersedia menyumbangkan darahnya untuk keselamatan ibu melahirkan sehingga bila terjadi sesuatu yang memerlukan darah segera bisa teratasi. Calon donor yang disiapkan harus memenuhi syarat sebagai pendonor darah untuk ibu seperti salah satunya calon pendonor tidak menderita penyakit infeksi seperti malaria, hepatitis dan HIV/AIDS.

g. Pemilihan kontrasepsi yaitu dimana kontrasepsi penting direncanakan saat kehamilan sehingga pada saat 42 hari ibu telah memiliki pilihan kontrasepsi yang tepat. Metode yang akan digunakan sebagai pedoman keluarga dalam memilih kontrasepsi dapat mengacu pada kriteria penggunaan kontrasepsi yang rasional. Kontrasepsi yang dapat dipilih oleh ibu dan suami seperti kontrasepsi IUD pascasalin, implan, suntik, pil, kondom, tubektommi serta pasektomi, dimana sebelumnya ibu dan suamisudah berkonsultasi kepada petugas kesehatan (dokter atau bidan).

2. Faktor-faktor yang mempengaruhi persiapan persalinan

a. Usia sangat berpengaruh terhadap perhatian dalam proses persalinan, karena semakin muda umur ibu maka semakin kurang perhatian serta pengalaman yang dimiliki ibu hamil karena ketidaksiapan ibu dalam menerima sebuah kehamilan. Hal ini akan berdampak buruk selama proses persalinan berlangsung. Umur yang ideal untuk 
menjadi ibu adalah antara 20-35 tahun karena dalam periode kehidupan wanita ini resiko menghadapi komplikasi medis paling rendah. Jika seorang wanita memutuskan untuk hamil di luar rentang usia tersebut maka akan rentan untuk mangalami kehamilan yang berisiko tinggi, baik secara fisik maupun psikis. Kehamilan pada usia 35 tahun keatas tersebut kehamilan yang akan menimbulkan risiko yang lebih besar (Rohani, 2011). Usia ibu secara garis besar menjadi indikator dalam kedewasaan dan setiap pengambilan keputusan yang mengacu pada setiap pengalaman.

b. Paritas berdasarkan penelitian Husna dan Sundari (2015), ibu multigravida akan lebih tenang menjalani persalinan karena mengulang pengalamannya yang dahulu. Ibu multigravida mempunyai pengalaman hamil dan bersalin yang lebih banyak, maka dapat mempengaruhi persiapan persalinannya.

c. Tingkat Pendidikan sangat mempengaruhi bagaimana seseorang untuk bertindak dan mencari penyebab solusi dalam hidupnya. Oleh karena itu orang yang berpendidikan akan lebih mudah menerima gagasan baru (Walyani, 2015). Pendidikan berkaitan erat dengan pengetahuan dan sikap ibu dalam menghadapi persalinan. Penelitian Putranti (2014) menyebutkan bahwa semakin baik pengetahuan dan sikap ibu hamil maka semakin baik pula kesiapan ibu dalam menghadapi persalinan. Penelitian Kabakyenga, Östergren dan Pettersson (2011) menyatakan bahwa ada hubungan tingkat pendidikan dengan kesiapan persalinan. Dapat disimpulkan bahwa kesiapan persalinan bisa dilakukan dari pendidikan apapun baik pendidikan SD, SMP, SMA maupun Perguruan Tinggi.

d. Pekerjaan berhubungan langsung dengan pendapatan atau kondisi ekonomi ibu dalam menghadapi persalinan. Penelitian Sumiati (2015) menyatakan bahwa ada hubungan kesiapan ekonomi keluarga dengan kesiapan ibu hamil dalam menghadapi persalinan. Keadaan sosial ekonomi sangat mempengaruhi kehamilan ibu karena berhubungan dengan pemenuhan kebutuhan-kebutuhan ibu selama kehamilan antara lain: makanan sehat, bahan persiapan kelahiran, obat-obatan, tenaga kesehatan dan transportasi/sarana angkutan.

\section{MATODE PENELITIAN}

Penelitian ini menggunakan desain pre eksperiment one group pretest-post test design. Populasi dalam penelitian ini sebanyak 218 orang ibu hamil wilayah kerja UPT Puskesmas Alas Barat pada bulan Januari 2020. Teknik pengambilan sampel menggunakan Total sampling dan didapatkan sapel sebnyak 102 orang ibu hamil dari total populasi 218 orang ibu hamil. Teknik pengumpulan data yang digunakan adalah dengan penyebaran kuesioner. Analisis data peneliti menggunakan Teknik analisis regresi yang dihitung dengan bantuan aplikasi SPSS versi 16.0 for windows.

Penelitian ini dilaksanakan di Kecamatan Alas Barat yang merupakan salah satu dari dua puluh empat kecamatan dalam wilayah Kabupaten Sumbawa sebelah barat. Dengan lokasi tersebut maka jaraknya dari Ibukota Propinsi Nusa Tenggara Barat (Mataram) kurang lebih $130 \mathrm{~km}$, sedangkan jarak dari Ibukota Kabupaten Sumbawa yaitu Sumbawa Besar kurang lebih $75 \mathrm{~km}$. Kecamatan Alas Barat sebesar 168,88 km2, yang terbagi habis dalam 8 desa. Semua desa di kecamatan Alas Barat masuk dalam wialayah kerja UPT Puskesmas Alas Barat. Pelaksanaan penelitian dilakukan dari bulan Februari - April tahun 2020.

\section{HASIL DAN PEMBAHASAN}

\section{Karakeristik Responden}

Berdasarkan penelitian yang telah dilakukan terhadap 102 ibu Hamil di wilayah kerja UPT Puskesmas Alas Barat didapatkan karaktteristik sebagai berikut:

a. Karakteristik Responden Berdasarkan Umur Tabel 4.1 Distribusi frekuensi karakteristik responden

\begin{tabular}{cccc}
\hline No & Umur & $\begin{array}{c}\text { Frekuensi } \\
(\mathrm{f})\end{array}$ & $\begin{array}{c}\text { Presentase } \\
(\%)\end{array}$ \\
\hline 1. & $<20$ & 3 & 2,9 \\
2. & $20-30$ & 63 & 61,8 \\
3. & $>30$ & 36 & 35,3 \\
& Total & 102 & 100,0 \\
\hline
\end{tabular}

(Sumber: data Primer, 2020)

Tabel 4.1 menunjukan bahwa dari 102 reponden sebagian besar memiliki umur rata-rata 30 tahun berjumlah 63 orang $(61,8 \%)$.

b. Karakteristik Responden Berdasarkan Tingkatan Penendidikan

Tabel 4.2 Distribusi Frekuensi Karakteristik Responden

\begin{tabular}{cccc}
\multicolumn{3}{c}{ Responden } \\
\hline No & Pendidikan & $\begin{array}{c}\text { Frekuensi } \\
(\mathrm{f})\end{array}$ & $\begin{array}{c}\text { Presentase } \\
(\%)\end{array}$ \\
\hline 1. & Dasar & 63 & 61,8 \\
2. & Menengah & 30 & 29,4 \\
3. & Tinggi & 9 & 8,8 \\
& Total & 102 & 100,0 \\
\hline
\end{tabular}

(Sumber: data Primer, 2020)

Tabel 4.2 menunjukan bahwa dari 102 reponden sebagian besar memiliki pendidikan dasar berjumlah 63 orang $(61,8 \%)$. 
c. Karakteristik Responden Berdasarkan Status Pekerjaan

Tabel 4.3 Distribusi Frekuensi Karakteristik Responden

\begin{tabular}{cccc}
\hline No & Pekerjaan & $\begin{array}{c}\text { Frekuensi } \\
(\mathrm{f})\end{array}$ & $\begin{array}{c}\text { Presentase } \\
(\%)\end{array}$ \\
\hline 1. & Bekerja & 75 & 73,5 \\
2. & Tidak Bekerja & 27 & 26,5 \\
& Total & 102 & 100,0 \\
\hline
\end{tabular}

(Sumber: data Primer, 2020)

Tabel 4.3 menunjukan bahwa dari 102 reponden sebagian besar tidak bekerja berjumlah 75 orang $(73,5 \%)$.

d. Karakteristik Responden Berdasarkan Umur Kehamilan Ibu

Tabel 4.3 Distribusi Frekuensi Karakteristik Responden

\begin{tabular}{cccc}
\hline No & Trimester & $\begin{array}{c}\text { Frekuensi } \\
\text { (f) }\end{array}$ & $\begin{array}{c}\text { Presentase } \\
(\%)\end{array}$ \\
\hline 1. & Trimester I & 16 & 15,7 \\
2. & Trimester II & 25 & 24,5 \\
3. & Trimester III & 61 & 59,8 \\
& Total & 102 & 100,0 \\
\hline
\end{tabular}

(Sumber: data Primer, 2020)

Tabel 4.3 menunjukan bahwa dari 102 reponden sebagian besar umur kehamilan berada pada Trimester III berjumlah 61 orang $(59,8 \%)$.

e. Karakteristik Responden Berdasarkan Jumlah Kehamilan

Tabel 4.3 Distribusi Frekuensi Karakteristik Responden

\begin{tabular}{cccc}
\hline No & Kehamilan & $\begin{array}{c}\text { Frekuensi } \\
(\mathrm{f})\end{array}$ & $\begin{array}{c}\text { Presentase } \\
(\%)\end{array}$ \\
\hline 1. & Gravida & 37 & 36,3 \\
2. & Multigravida & 65 & 63,7 \\
& Total & 102 & 100,0 \\
\hline
\end{tabular}

(Sumber: data Primer, 2020)

Tabel 4.3 menunjukan bahwa dari 102 reponden sebagian besar merupakan ibu Multigravida berjumlah 65 orang $(63,7 \%)$.

Hasil uji analisis tersebut, dapat diketahui bahwa nilai signifikansi Regresi variabel layanan persiapan persalinan terhadap persiapan persalinan sebesar 0,000 atau lebih kecil 0,05 . Dengan demikian hipotesis yang menyatakan bahwa Layanan Persiapan Persalinan (Edukasi dan Senam Hamil) berpengaruh signifikan terhadap Persiapan Persalinan Ibu Hamil di wialayah kerja UPT Puskesmas Alas Barat.

Hasil analisis koefisien determinas (RSquare), menyatakan bahwa besarnya koefisien determinasi adalah sebesar 0,386. Hal ini berarti bahwa besar pengaruh variabel Layanan Persiapan Persalinan (Edukasi dan Senam Hamil) terhadap Persiapan Persalinan Ibu Hamil sebesar 14,9\% selebihnya dibentuk oleh faktor diluar penelitian. Nilai R square sebesar 0,377 menunjukkan bahwa adanya pengaruh variabel $\mathrm{X}$ yaitu Layanan
Persiapan Persalinan (Edukasi dan Senam Hamil) terhadap variabel Y yaitu Persiapan Persalinan Ibu Hamil.

Nilai koefisien regresi Layanan Persiapan Persalinan (Edukasi dan Senam Hamil) menunjukkan bahwa arah pengaruh variabel $\mathrm{X}$ ke variable $\mathrm{Y}$ itu positif dan besar pengaruhnya sebesar 0,489.

\section{KESIMPULAN}

Berdasarkan hasil penelitian yang dilakukan pada 102 responden mengenai Inovasi Layanan Persiapan Persalinan (Edukasi dan Senam Hamil) pada Ibu Hamil di Wilayah Kerja UPT Puskesmas Alas Barat dapaat ditarik kesimpulan bahwa terdapat pengaruh Layanan Persiapan Persalinan

(Edukasi dan Senam Hamil) terhadap Persiapan Persalinan Ibu Hamil di Wilayah Kerja UPT Puskesmas Alas Barat dengan nilai signifikansi Regresi sebesar 0,000 atau lebih kecil 0,05.

Adapun saran, yang penulis dapat rekomendasikan dari hasil penelitian adalah:

1. Bagi ibu hamil

Ibu Hamil diharapkan lebih berperan aktif dalam mengikuti kegiatan yang berhubungan dengan kehamilan dan persalinan selama kehamilan agar ibu memiliki pengetahuan tentang kebutuhan selama hamil terutama persiapan menghadapi persalinan sehingga dapat meminimalisir kegawatdaruratan pada ibu maupun janin saat proses persalinan.

2. Bagi bidan UPT Puskesmas Alas Barat

Diharapkan kepada bidan UPT Puskesmas Alas Barat dapat memberikan edukasi persaiapn persalinan dan melaksanakan senam hamil lebih sering secara rutin untuk meningkatkan pengetahuan ibu hamil tentang proses persalinan dan mempersiapakan persalinananya sejak dini.

3. Bagi Peneliti Selanjutnya

Diharapkan dapat mengembangkan penelitian ini lebih lanjut.

\section{REFERENSI}

Depkes R.I. (2009) Pedoman Program Perencanaan Dan Pencegahan Komplikasi (P4K) dengan stiker. 2009. 2009:12 of 50.

Dinas Kesehatan Kabupaten Sumbawa. (2018). Profil Kesehatan Kabupaten Sumbawa Provinsi Nusa Tenggara Barat.

Gebre, M., Gebremariam, A., and Abebe, T. A. (2015). Birth Preparedness and Complication Readiness among Pregnant Women in Duguna Fango District, Wolayta Zone , 103, 1-12.

Hailu, M., Gebremariam, A., Alemseged, F., and Deribe, K. (2011). Birth Preparedness and Complication Readiness among Pregnant Women in Southern Ethiopia. https://www.ncbi.nlm.nih.gov/pmc/articles/P 
MC3120869/pdf/pone.0021432.pdf diakses 19 juni 2020.

Husna, Sundari. (2015). Persiapan Persalinan Ibu Hamil Ditinjau Dari Jumlah Persalinan Dan Jumlah Kunjungan Kehamilan. Dinamika Kesehatan Vol.6 No. 1 Juli 2015. file://C:/Users/asus/Downloads/86-133-1SM\%20(1).pdf diakses 19 Juni 2020.

Irianti B, Halida EM, Duhita F. (2014). Asuhan Kehamilan Berbasis Bukti : Jakarta:Sagung Seto.

Kabakyenga, J. K., Östergren, P., Turyakira, E., and Pettersson, K. O. (2011). Knowledge of obstetric danger signs and birth preparedness practices among women in rural Uganda https://reproductive-health journal.biomedcentral.com/track/pdf/10.1186/ 1742-4755-8-33 diakses 20 juni 2020

Kementrian Kesehatan RI. 2011. Informasi Jampersal (Buku Saku jampersal). Pusat Promosi Kesehatan : Jakarta.

Mubarak, Wahit Iqbal. (2012). Promosi Kesehatan Untuk Kebidanan. Jakarta: Salemba Medika

Notoatmodjo. (2011). Kesehatan Masyarakat: Ilmu dan Seni. Jakarta: Rineka Cipta.

Putranti, V. (2014). Hubungan Pengetahuan dan Sikap Tentang Persalinan Dengan Kesiapan Primigravida Menghadapi Persalinan. Tesis. Surakarta : Universitas Sebelas Maret.

Rafika, (2028). Efektifitas Prenatal Yoga terhadap Pengurangan Keluhan Fisik pada Ibu Hamil
Trimester III. Jurnal Kesehatan Volume 9, Nomor 1, April 2018 ISSN 2086-7751 (Print), ISSN 2548-5695. http://ejurnal.poltekkestjk.ac.id/index.php/JK diakses 20 juni 2020

Sumiati dkk (2015). Faktor-Faktor Yang Mempengaruhi Kesiapan Ibu Hamil Dalam Menghadapi Persalinan Di Ruang Bersalin Rumah Sakit Umum Labuang Baji Makassar. Jurnal Ilmiah Kesehatan Diagnosis Vol. 5, No. $6 \quad$ tahun 2015. https://jurnalstikesnh.files.wordpress.com/201 6/11/5615713719_2302-1721.pdf diakses 12 Mei 2020

Rohani. (2011). Asuhan Kebidanan Pada Masa Persalinan. Jakarta : Salemba Medika

Walyani \& Purwoastuti. (2015). Asuhan Kebidanan, persalinan dan bayi baru lahir. Yogyakarta: Pustaka Barupess.

Walyani, Elisabeth Siwi (2015). Asuhan Kebidanan Pada Kehamilan. Yogyakarta: Pustaka Barupess.

Wijaya, D. E., Rillyani, Wandini, R., \& Wardiyah, A. (2015). Pengaruh Pendampingan Suami Terhadap Lamanya Persalinan Kala II di Ruang Delima RSUD DR.H. Abdul Moeloek Lampung. Jurnal Keperawatan, 6, 6-14.

World Health Statistics. (2017). https://www.who.int/gho/publications/world _health_statistics/2017/EN_WHS2017_Part 1.pdf?ua $=1$ 